International Journal of Engineering \& Technology, $7(1.1)(2018)$ 346-349
International Journal of Engineering \& Technology
Website: www.sciencepubco.com/index.php/IJET
Research paper

\title{
UPFC based transmission line power load flow control under different operating methods
}

\author{
K Lingaswamy ${ }^{1}$ *, T Anil Kumar ${ }^{1}$, G Hari Krishna ${ }^{1}$, N Shiva Prasad ${ }^{1}$ \\ ${ }^{1}$ Department of Electrical and Electronics Engineering, Institute of Aeronautical Engineering, Hyderabad, India-500043 \\ *Corresponding author E-mail: kandadilingareddy@gmail.com
}

\begin{abstract}
In this paper the methods to control operation of shunt and series inverters using power flow controller (UPFC) is analyzed with real power flow in power system transmission line. These operation mode using UPFC are executed to reduce Swaying in the control framework transport. The execution about every system may be resolved toward the predefined administrative control. Those arrangement What's more shunt converter working under four separate blending from claiming working modes may be used to ponder An example force framework organize. The line flow in MW oscillation damping is predicated with various modes of operations and verified same with MATLAB/ SIMULINK.
\end{abstract}

Keywords: Unified Power Flow Controllers (UPFC); Power Flow Control; Operating Modes; Sssc; Statcom.

\section{Introduction}

In recent years, the Flexible AC Transmission System (FACTS), one of the power electronics devices proposed an outlook to boost power transfer capability, controllability and stability of AC transmission systems [1]. It will be watched that those energy stream control of transmission lines may be normally confined with extensive indicator solidness. A bound together control stream controller (UPFC) may be a multipurpose Realities controller, which camwood control at the same time large portions parameters for example, line impedance, voltage Also its stage point. Both the arrangement Furthermore shunt converters of UPFC need aid proficient from claiming absorbing alternately generating sensitive force independently [2]. Kalyani et al explored the control scheme exploring individual control of real and reactive power and tested the developed model by applying different faults across a transmission line.

The proposed control scheme has been found successful in power swings in transient states [3]. The controllers for coordination of real power and reactive power in the UPFC control system have shown good recital during transient as well as steady conditions [4]. Various control schemes of the series compensator has been discussed by Huang et at [5] as UPFC consist of shunt and series inverter with their different operating control modes. The different control modes of UPFC which can control voltage, its phase angle and line impedance, direcly are discussed by many researchers for improving the line flows and power system stability. Modes of UPFC improving line flows. Likewise the UPFC's infusion model is utilized permitting three parameters to a chance to be simultaneously controlled to be specific magnitude, point of the injected arrangement voltage and the shunt sensitive energy [9], [10].

True energy and sensitive force flows, freely of the transmission line are regulated Toward UPFC Similarly as suggested
[11]. UPFC need that ability about naturally damping oscillations alongside the transmission line control.

Comparison of the different techniques proposed for line flows is also presented in this work.

\section{Proposed system}

This paper is organized in four sections: Section-II presents the UPFC Control with various operating modes. In Section-III, Simulation Results have been discussed. The Conclusion and References are given in Section IV \& V respectively.

Those UPFC camwood make worked in distinctive working modes depending upon those force framework parameters on a chance to be regulated. The arrangement What's more shunt inverter voltages demonstrated On fig. 1 would regularly controlled Eventually Tom's perusing evolving the regulation list $\mathrm{m}$ What's more stage point 6 . These indices need aid confirmed by the UPFC control framework depending upon the fancied transport streams What's more transport bar voltage which need aid further dictated Eventually Tom's perusing the energy framework conditioner Also boss [13].

The modeling of UPFC is described with the standard equations of UPFC (1), (2) \& (3) Control of Power flow and power system stabilization with one of these modes has been implemented by Morioka et al [6] [7] \& [8]. Although various control strategies had been discussed in the literature, less had been talked about the use of operating The relations between ac and dc voltages are

$$
\mathrm{V}_{1}=\mathrm{m}_{1} \mathrm{~V}_{\mathrm{d}} / \mathrm{V}_{\mathrm{B}} \mathrm{V}_{2}=\mathrm{m}_{2} \mathrm{~V}_{\mathrm{d}} / \mathrm{V}_{\mathrm{B}}
$$




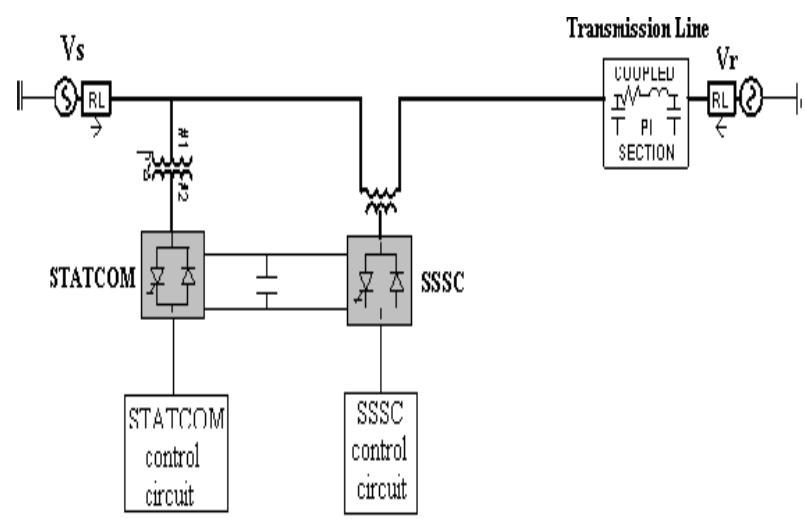

Fig. 1: UPFC and Its Control in A Transmission Line.

Where $m_{1}$ and $m_{2}$ are the coefficients representing the PWM control. $\mathrm{P}_{1} \& \mathrm{P}_{2}$ are the real power transfer with the ac system in pu. $X_{t 1}, n_{1}$, and, $X_{t 2}, n_{2}$ are the reactance and the voltage ratios of the shunt and series transformer respectively. $V_{S}$ and $V_{R}$ are the sending and receiving end voltages. $S_{B}$ is the MVA base of the system.

Further, the UPFC control is categorized into two main operating control modes: Shunt and Series

\subsection{Shunt VSC operating modes}

This mode of shunt converter allows operating in such a way so as to introduce a suitable current, in the transmission line. The current is divided into two components w.r.t the line voltage: real component, in phase or in opposite phase with the line voltage, and the reactive component, in quadrature with the line voltage. The genuine part may be naturally assessed for that need should harmony the true force of that arrangement inverter. The sensitive component, on the different hand, might make independently altered to any wanted reference level (inductive alternately capacitive) by absorbing or generating sensitive energy separately starting with those transport. The control from claiming shunt converter could be finished over two modes [1].

\subsection{Voltage regulation control mode}

i) VAR Control Mode

The input values are set for inductive/ capacitive VAR in this mode. With the control of shunt inverter, the VAR reference is converted to a corresponding shunt current requirement by adjusting gate signals of the inverter to determine the desired current.

ii) Voltage Regulation Control Mode

The control of quadrature component of shunt current results to sustain the transmission line voltage to a preset reference value at the summation point in this mode.

iii) Series VSC Operating Modes

With these operating modes of series VSC, the output is obtained when a series voltage with transmission line is injected by a series inverter. These control modes should follow the preset operating limits. The various series operating modes of UPFC are given below [14]

a) Direct Voltage Injection Mode (DVIM): The set inputs are the magnitude and phase angle of the series voltage in this operating mode

b) Phase Angle Control Mode (PACM) : The phase displacement is determined between the sending and the receiving end voltage which further results in the reference input in this mode

c) Line Impedance Control Mode (LICM): The reference signal is impedance value which is introduced in series with the line impedance in this mode.

d) Automatic Power Flow Control Mode (APFCM): The angle and magnitude of the injected voltage vector, is controlled with a line current vector, I, so that preferred real and reactive power flows are obtained in the line.

\section{Simulation results}

A test system of single machine with infinite bus system (SMIB) is presented in Fig. 2. The system has been designed in MATLAB/ SIMULINK to analyze the effect of the control algorithm of the UPFC on line flows The SMIB consists of a alternator (1200 MVA rating) tied to a transmission system through two transformers $\mathrm{T}_{\mathrm{r} 1}, \mathrm{~T}_{\mathrm{r} 2}$ of rating $500 \mathrm{KV} 1000 \mathrm{MVA}$ and $500 \mathrm{KV}, 900 \mathrm{MVA}$ respectively. The transmission system consists of $230 \mathrm{kV}$ double circuit transmission line L1 of length $75 \mathrm{~km}$ and $500 \mathrm{kV}$ two single transmission lines L2 and L3 of $60 \mathrm{~km}$ each. Synchronous generator comprises an excitation system, speed regulator, a power system stabilizer (PSS) etc.

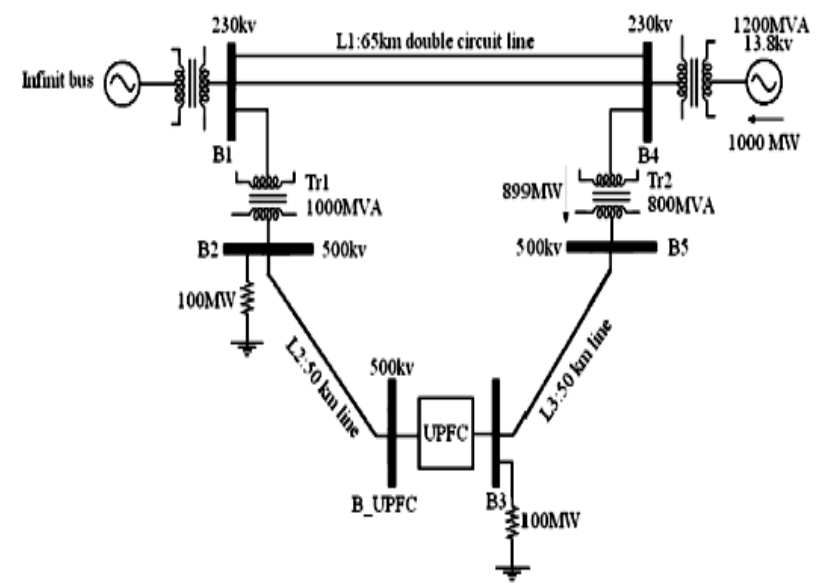

Fig. 2: Single Machine Infinite Bus System (SMIB) with UPFC

UPFC is installed in the right end of line L2. Shunt inverter of UPFC is tested with two modes that is VAR mode and Voltage regulation. Similarly, Series converter is provided with two operating modes which are APFCM and DVIM. So to study the effect of UPFC on the power system, four combinations of operating modes with two of shunt and two of series inverter are tested on a system shown in Fig.2.

Results for Real power through transformer bank Tr2 with and without UPFC are shown in Table

Table 1: Real Power Flow with Different Operating Modes of UPFC

\begin{tabular}{|c|c|}
\hline Operation on SMIB system & $\begin{array}{l}\text { Real power flow through } \\
\text { B4 Max value- ( } 900 \mathrm{MW})\end{array}$ \\
\hline Without UPFC & $999 \mathrm{MW}$ \\
\hline $\begin{array}{l}\text { UPFC with shunt inverter in } \\
\text { VAR } \\
\text { mode, series inverter in Power } \\
\text { Flow Mode }\end{array}$ & 896MW \\
\hline $\begin{array}{l}\text { UPFC with shunt inverter in } \\
\text { VAR } \\
\text { mode, series inverter in Manual } \\
\text { Voltage Injection Mode }\end{array}$ & 924MW \\
\hline $\begin{array}{l}\text { UPFC with shunt inverter in } \\
\text { Voltage } \\
\text { regulation mode, series inverter } \\
\text { in Power Flow Mode }\end{array}$ & $896 \mathrm{MW}$ \\
\hline $\begin{array}{l}\text { UPFC with shunt inverter in } \\
\text { Voltage regulation mode, series } \\
\text { inverter in } \\
\text { Manual voltage Injection Mode }\end{array}$ & 922MW \\
\hline
\end{tabular}

During load flow analysis, transformer bank Tr2 gets overloaded. As shown in the table, power flow through the $\operatorname{Tr} 2$ is more 
than its rating without UPFC. With the four combinations of operating modes of UPFC, the line flows through $\operatorname{Tr} 2$ are shown.

It has been determined that employing both the shunt modes of shunt inverter and APFCM of series inverter of UPFC in a system shown in Fig. 2, the amount of real power flow is below its rating as compared to the system without UPFC. The amount of power flow using both the shunt modes of shunt inverter and DVIM of series inverter is decreased as compared to the system without UPFC but is above the rating of transformer 2 .

Further a three phase fault of duration $0.2 \mathrm{~s}$ has been considered at the instant $5 \mathrm{sec}$ from start of simulation for verifying the performance of UPFC without removing any lines as shown in the Figure 3.

The Power Flow Characteristics (in p.u) for the Transformer $\mathrm{Tr} 2$ with the both Voltage Regulator mode and VAR mode of shunt inverter and APFCM, of series inverter mode of UPFC are shown in Fig 3 \& Fig. 4. It is pragmatic from both the characteristics that real power is improved with UPFC as compared to without UPFC with the three phase fault. Supervisors in a power flow mode are so set as to control the power flow in a transmission line. The oscillations are increased at the instant of fault but after that these

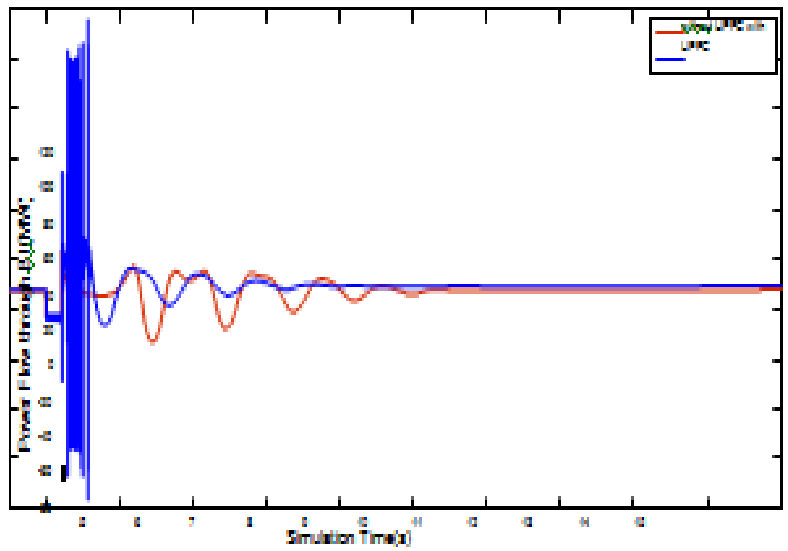

Fig. 3: Power Flow with Voltage Regulation Mode of Shunt Inverter and APFCM of UPFC.

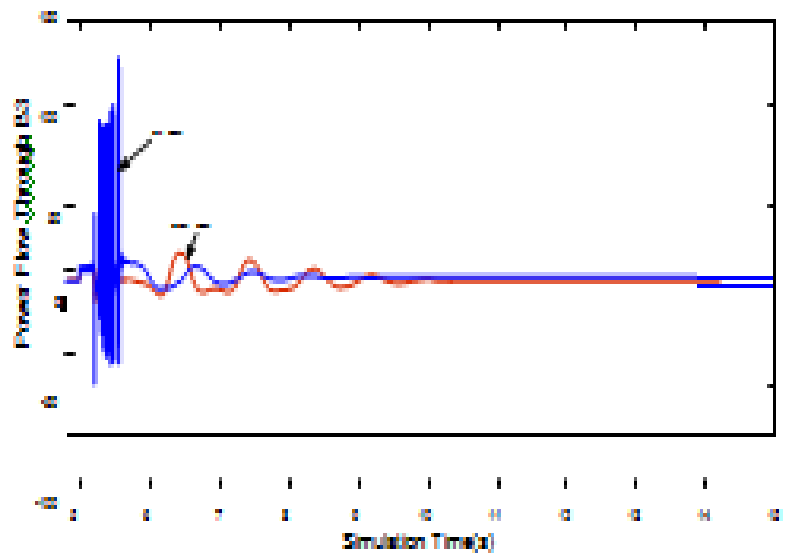

Fig. 4: Power Flow with VAR Mode of Shunt Inverter and APFCM of UPFC.

Oscillations are damped and settled with the APFCM as shown in Fig. 3 \& Fig.4. The Power Flow Characteristics (in p.u) for the Transformer $\operatorname{Tr} 2$ with the both Voltage Regulator mode and VAR mode of shunt inverter and DVIM, of series inverter mode of UPFC are shown in Fig 5 \& Fig. 6.

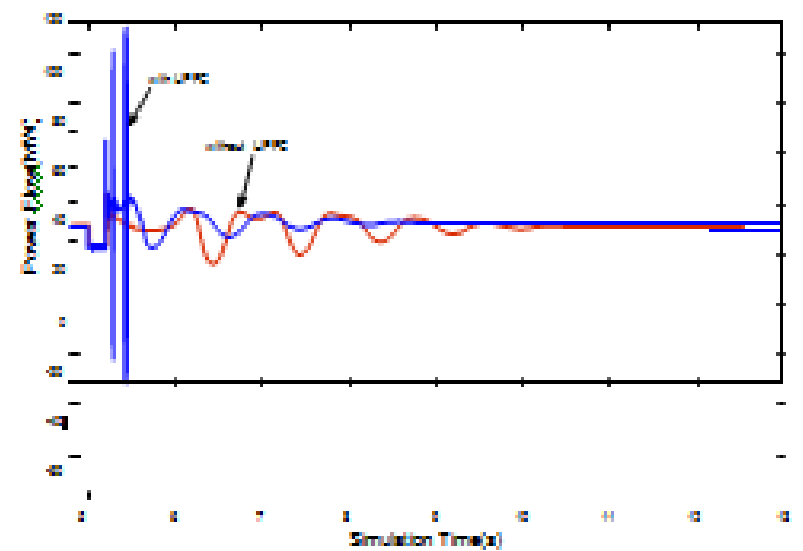

Fig. 5: Power Flow with Voltage Regulation Mode of Shunt Inverter and DVIM of UPFC.

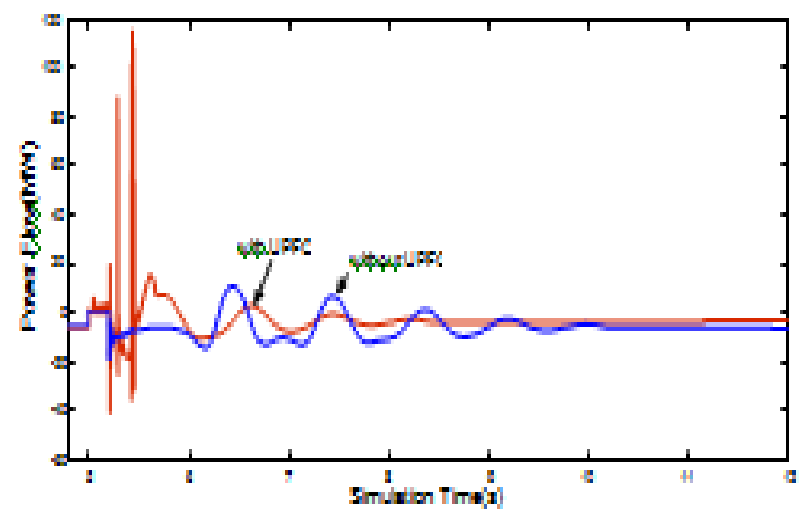

Fig. 6: Power Flow with VAR Mode of Shunt Inverter and DVIM of UPFC.

It is clear from both the characteristics that although there is improvement of power flow with UPFC as compared to without UPFC but oscillations are less damped with manual voltage injection mode as compared to power flow mode of series inverter of UPFC. The values of Direct and Quadrature component of voltage are so set that the power during first Swing is increased but there are long oscillations in the system. Few oscillations are produced with the DVIM as shown in Fig.5 and Fig. 6 at the instant of fault but after the oscillations remained for longer time.

\section{Conclusion}

Different operating modes of shunt Also arrangement inverter for UPFC would investigate in this paper. These operating modes would try for force stream Investigation for the three period hamper deficiencies in the control framework system. A test control framework organize will be viewed as Also tried to Different working modes with figure out the control stream through an over-burden transport. It might have been discovered that for the utilization of Different combinations for shunt Also arrangement inverter modes for UPFC to a organize. The sample network considered is relieved from overloading. By using the four combinations of operating modes of shunt and series converter, it was concluded that the best results were found for load flow analysis when series inverter is operating in Power flow mode irrespective of the shunt inverter mode of UPFC. Also with the power flow mode, the oscillations are more promptly damped as compared to the DVIM

\section{Acknowledgement}

The writer might want to much thanks to those division about department of science and technology and editorial manager and 
the unacknowledged reviewers to their valuable remarks what's more feedback

\section{References}

[1] Hingorani N.G. and L.Gyugui, "Understanding FACTS", IEEE Press, New York 2000

[2] E. Gholipour, S.Saasate, "Improving of Transient Stability of Power Systems Using UPFC”, IEEE Trans. On Power Delivery, vol. 20, No.2, pp. 1677-1682, 2005 https://doi.org/10.1109/TPWRD.2005.846354.

[3] S.Tara Kalyani, G. Tulasiram Das, "Simulation of D-Q Control System for a Unified Power Flow Controller", ARPN Journal of Engineering and Applied Sciences, Vol. 2, No. 6, December 2007

[4] Liming Liu, Pengcheng Zhu, Yong Kang, Jian Chen, "Power- Flow Control Performance Analysis of a Unified Power-Flow Controller in a Novel Control Scheme", IEEE Transactions onPower Delivery, Vol. 22, No. 3, July 2007.

[5] Zhengyu Huang, Yixin Ni, C. M. Shen, Felix F.Wu, Shousun Chen, and Baolin Zhang "Application of Unified Power Flow Controller in Interconnected Power Systems-Modeling,Interface, Control Strategy, and Case Study'IEEE Transactions on Power Systems, Vol. 15,No. 2, May 2000.

[6] Yasuo Morioka, Masanao Kato, Yasuhiro Mishima, Yoshik Nakachi, "Implementation of Unified Power Flow Controller and Verification for Transmission Capability Improvement" IEEE Transactions on Power Systems, Vol. 14, No.2, May 1999. https://doi.org/10.1109/59.761883.

[7] X.-P. Zhang, "Comprehensive modelling of the unified power flow controller for power system control", Springer-Verlag 2005.

[8] Xiao-Ping Zhang, Keith R. Godfrey, "Advanced Unified Power Flow Controller for Power System Steady State Control", IEEE Conference on Electric Utility Deregulation, Restructuring and Power Technologies,2004 Vol.1,pp.228-233.

[9] M. Noroozian, L. Ängquist, M. Ghandhari, and G. Andersson, "Use of UPFC for optimal power flow control", IEEE Trans. Power Delivery, vol. 17 , no. 4, October 1997, pp. 1629-1634. https://doi.org/10.1109/61.634183.

[10] G. Andersson, "Improving power systems dynamics by seriesconnected FACTS devices," IEEE Trans. Power Delivery, vol. 12, no. 4, October 1997, pp. 1636-1642

[11] Gyugi L."Reactive Power Generation and Control by Thyrisror Circuits". IEEE trans. Ind. Appl., vol.15, No. 5. Pp.521-532. Sept/Oct.1919

[12] Noroozian M. and Andersson G. "Power Flow Control by Use of Controllable Series Components". IEEE Tram on Power Delivery. vol. 8, No. 3, pp. 1420-1429, July 1993. https://doi.org/10.1109/61.252669.

[13] C.-T. Chang and Y.-Y. Hsu, "Design of UPFC controllers and supplementary damping controller for power transmission control and stability enhancement of a longitudinal power system", IEE Proc. Generation, Transmission, Distribution Vol.149. No. 4, July 2002, https://doi.org/10.1049/ip-gtd:20020199.

[14] L. Gyugi, C. D. Schauder, S. L. Williams, T. R. Rietman, D.R Torgerson, A.Edris, "The Unified Power Flow Controller: A New Approach To Power Transmission Control" ,IEEE Transactions on Power Delivery, Vol.10, No.2, April 195

[15] Farmer, DB; Gordon, RG (2006). "Atomic layer deposition on suspended single-walled carbon nanotubes via gas-phase noncovalent functionalization". Nano letters. 6 (4): 699-703. https://doi.org/10.1021/n1052453d.

[16] Cao, J; Wang, Q; Dai, H (2005). "Electron transport in very clean, as-grown suspended carbon nanotubes". Nature Materials. 4 (10): 745-9. https://doi.org/10.1038/nmat1478.

[17] Sangwan, V. K.; Ballarotto, V. W.; Fuhrer, M. S.; Williams, E. D. (2008). "Facile fabrication of suspended as-grown carbon nanotube devices". Applied Physics Letters. 93 (11): 113112. https://doi.org/10.1063/1.2987457.

[18] .Lin, Yu-Ming; Tsang, James C; Freitag, Marcus; Avouris, Phaedon (2007). "Impact of oxide substrate on electrical and optical properties of carbon nanotube devices" (PDF). Nanotechnology. 18 (29): 295202. https://doi.org/10.1088/0957-4484/18/29/295202

[19] Javey, Ali; Guo, Jing; Wang, Qian; Lundstrom, Mark; Dai, Hongjie (2003). "Ballistic carbon nanotube field-effect transistors" (PDF). Nature. 424 (6949): 654-7 https://doi.org/10.1038/nature01797.

[20] Avouris, Phaedon; Chen, Zhihong; Perebeinos, Vasili (2007). "Carbon-based electronics". Nature Nanotechnology. 2 (10): 605-15. https://doi.org/10.1038/nnano.2007.300.
[21] P. Avouris et al, "Electronics and Optoelectronics with Carbon Nanotubes," Archived October 8, 2010, at the Wayback Machine. American Institute of Physics, 18-21, June/July 2004. 